\title{
Carvalho, Bruno. Porous City: A Cultural History of Rio de Janeiro (from 1810s Onward). Liverpool: Liverpool University Press, 2013.
}

Detailed, lucid, judicious, and engaging, this cultural history of Rio de Janeiro incites interest via its uncovering of the many socio-historical and cultural layers embedded in the urban memory of a city that radiates socio-cultural and ethno-racial mixtures while simultaneously stratifying such elements economically, racially, and socially. Never skirting the inherent contradictions and socio-economic inequities historically prevalent in Brazil's former national capital, emblematic of many other cities in the nation and abroad, Porous City does indeed capture how a proclivity for cultural porosity with its ebbs and flows contributes to the definition and reformulation of urban spaces and how that porosity conveys indelible social ramifications. Drawing from literature, history, music, and urban sociology, this erudite, doggedly researched and theoretically au-courant study exudes bountiful insights about cultural mixture, rising above threadbare images and the myths of a city known for celebrating its own multi-racial and natural beauties while camouflaging its violent injustices. The selection of porosity as an overarching concept is felicitous here because the image of permeable yet perhaps not permanent membership more aptly addresses the realities of Brazilian social congress across racial and socioeconomic lines. According to Carvalho, this congress manifests inclusion and exclusion as permeable boundaries, thereby showing how porosity and ambivalence, as part of the Brazilian ethos, are more accurate terms than such heavily charged words as miscegenation, syncretism, or hybridity.

Porous City traces the rise and destruction of a unique urban space within Rio de Janeiro, not too distant from its Center, known as the Cidade Nova. This study guides the reader through this space via an accessible historical writing style, from the moment the Portuguese court arrives in Brazil in 1808, through the 1870s with the hustle and bustle of crowds and streetcars as the city edges closer to the end of Empire. This historical and cultural span continues up through the tropical Belle Époque with its pervasive urban reforms, hinting at future urban divisions, followed by the heyday of the musical 1920s and the vibrant Afro-Brazilian and Jewish Praça Onze neighborhood, down through 
the cultural price of progress under the Vargas Regime and then closing with the Cidade Nova's demise and its impending erasure. By centering upon one cultural space such as the Cidade Nova, Carvalho explores its metonymic cultural reverberations and socio-historical circumstances, which became emblematic of Brazil's porous two-way social tendencies and practices. Moreover, porosity is delineated by rediscovering a neighborhood's spatial and social heterogeneous role as crucible in the formulation of a multi-cultural gestalt. The city's historical profile comes into sharper focus from the viewpoint of how one urban space responds to top-down planning via its bottom-up realities.

Although literature, cinema and painting are employed to relate to Cidade Nova's memorable past, the power of music strongly permeates this study with vivid references to geographically referential samba lyrics and rhythms and other forms of popular music, transmitting social attitudes, preoccupations, protests, and disparities. From an artistic stance, the Cidade Nova space becomes an exemplary showcase to illustrate how, while facing an urban modernizing push, artists still engaged highly creative expressions by supposedly undesirable and "dangerous" groups or races viewed as a threat to Brazil's progress and modernity. In this vein, Carvalho juxtaposes the Latin American view of a lettered city or cartographies alongside new non-lettered expressions, identifying the emerging oral and visual forms of cultural meaning and production that contributed in disparate ways to Rio's ever-evolving cultural cityscape.

The scope of the literary analyses in this study begins foremost with new readings of such canonical texts as Manuel Antonio de Almeida's Memórias de um sargento de milícias, a nineteenth-century novel whose original outlook is non-elite and, furthermore, is sparked by a narrative manifesting how the spoken word from "lá para as bandas," where gypsies and other "misfits" lived, infiltrated the old, lettered city. With attention to Machado de Assis's short stories, Carvalho reads the master's geographical mapping of Rio's streets and neighborhoods as porous and zeroes in on the permeable social relations of agregados, a peculiar categorization bridging different social classes. Other literary treatments, for example, center upon the journalist João do Rio, Brazil's notable flaneur, who chronicled the life of Rio's salons and streets where Carnival emerges as an ever-rising sociocultural phenomenon. And Lima Barreto's 
failed attempts at bridging the center/periphery gap with a colloquial language unappreciated by the lettered elites elucidates the insidious resistance to cultural permeability. Yet Chiquinha Gonzaga, one of Brazil's more notable composers and pianists, is portrayed here as "freeing" Brazil's popular music.

In a notable chapter, Porous City focuses upon the Afro-Jewish Quarter of Praça Onze, where the population of "Little Africa" shared the same sociocultural space with Eastern European Jews, evidence of the integrative aspect of this neighborhood. Portrayed as a confluence of cultures, Praça Onze is interpreted as uniting diverse cultural backgrounds; poetry by Manuel Bandeira and the paintings of Lasar Segall also capture the multi-racial conviviality of the Mangue area, amidst houses of prostitution and dance halls. In addition to Brazilian writers, this study also draws upon the Brazilian experiences of foreigners such as the émigré Stefan Zweig and Hollywood's Orson Welles, interpreting the latter's sensitive artistry in focusing It's All True on contradictory and positive interactions of cultural porosity in Praça Onze in opposition to the State's problematic image of uncomplicated socio-racial integration.

From Porous City to Divided City and to today's hopeful Integrated City, Bruno Carvalho's erudite and expansive volume, while representing a veritable landmark study in Brazilian cultural studies, above all, affords a daring redefinition of Brazil's porous ethos-seductive but decidedly undemocratic. Via analyses of positive and negative porosities, the concept is never overstated or celebratory. In this sense, the reader gleans a balanced view of Brazil's permeability by way of this intellectual journey through many levels of Brazilian urban discourses. Herein, Rio de Janeiro's past yet memorable and fluid urbanity defies erasure in light of this study's focus upon the cityscape's cultural vestiges as relived via literature, history and music.

\section{Nelson H. Vieira}

Brown University 